\title{
Limited effect of rehabilitation for preventing a decrease in functional status after community- acquired pneumonia in elderly patients
}

Hao Chen ( $\nabla$ chinksmd@yahoo.co.jp )

Yokohama Shiritsu Daigaku https://orcid.org/0000-0003-3074-2235

Yu Hara

Yokohama Shiritsu Daigaku Fuzoku Byoin

Nobuyuki Horita

Yokohama Shiritsu Daigaku Fuzoku Byoin

Yusuke Saigusa

Yokohama Shiritsu Daigaku

Yoshihiro Hirai

Kanto Rousai Hospital

Takeshi Kaneko

Yokohama Shiritsu Daigaku Fuzoku Byoin

Research article

Keywords: community-acquired pneumonia, functional status, rehabilitation, senior

Posted Date: September 15th, 2020

DOI: https://doi.org/10.21203/rs.3.rs-36714/v2

License: (9) (i) This work is licensed under a Creative Commons Attribution 4.0 International License.

Read Full License 


\section{Abstract}

Background: Functional status (FS) is often decreased after hospitalization in elderly communityacquired pneumonia (CAP) survivors. Rehabilitation has frequently been used to prevent decreased FS. This study was designed to evaluate the effect of rehabilitation for preventing decreased FS.

Methods: This retrospective, observational study was conducted in two medical facilities from January 2016 to December 2018, and hospitalized CAP patients $>64$ years of age were enrolled. FS was assessed by the Barthel Index (BI) (range, 0-100, in 5-point increments) at admission and before discharge and graded into three categories: independent, BI 80-100; semi-dependent, BI 30-75; and dependent, BI 0-25. Multivariable analysis of factors contributing to decreased FS was conducted with two groups: with a decrease of at least one category (decreased group), or without a decrease of a category (maintained group). Then, the effect of rehabilitation was examined by propensity score analysis by adjusting factors contributing to decreased FS determined in the previous multivariable analysis.

Results: The maintained group included 400 patients, and the decreased group included 138 patients. The decreased group had a high frequency of rehabilitation therapy (189 (47.3\%) vs 104 (75.4\%); $\mathrm{p}<0.001)$. Multivariable analysis showed that factors affecting FS were length of stay, aspiration pneumonia, age, and Pneumonia Severity Index (PSI) of category V (odds ratio 1.05, 95\% Cl 1.04-1.07; $2.66,95 \% \mathrm{Cl} 1.58-4.49 ; 1.05,95 \% \mathrm{Cl} 1.02-1.09$; and $1.92,95 \% \mathrm{Cl} 1.29-3.44$; respectively). After adjusting for factors contributing to decreased FS, rehabilitation showed a limited effect in preventing a decreased FS in 166 matched pairs $(p=0.327)$.

Conclusions: The effect of rehabilitation was still unclear in CAP, and further research is warranted to find an effective way to conduct rehabilitation.

\section{Background}

Pneumonia is causing an increasingly higher proportion of deaths worldwide, with 3.2 million estimated deaths globally each year, exceeding all other infections including tuberculosis, HIV infection, and malaria.[1] Community-acquired pneumonia (CAP) is one of the most common medical causes of admission in most healthcare institutions in the USA.[2] In Japan, pneumonia is the third highest cause of death among elderly patients.[3]

Besides the high mortality in elderly CAP patients, these patients also experience deterioration of functional status (FS), an important component of quality of life for older adults and their caregivers, both during and after treatment [4]. Decreased FS prolongs length of stay (LOS) in elderly CAP patients [5], and the prevalence of functional decline was reported to be $8.6 \%-20 \%$ in CAP $[5,6]$. Early rehabilitation therapy might improve activities of daily living (ADL) during hospitalization in patients with aspiration pneumonia, but it may increase LOS [7]. The effect of rehabilitation in preventing decreased FS in CAP has remained unclear. Therefore, this study was designed to identify factors related to decreased FS and evaluate the effect of rehabilitation in preventing decreased FS in elderly CAP patients. 


\section{Methods}

This was a retrospective, cohort study of inpatients admitted to a community-based hospital and a teaching hospital in Japan from January 2015 to December 2018. This study was approved by the institutional review boards of the hospitals and conformed to the provisions of the Declaration of Helsinki (as revised in Brazil 2013).

\section{Definitions}

FS was evaluated at admission and before discharge by the Barthel Index (BI) [8] (range, 0-100, in 5point increments) of ADL and was graded into three categories according to the $\mathrm{BI}$ : independent, $\mathrm{BI} 80-$ 100; semi-dependent, BI 30-75; and dependent, BI 0-25 [9]. A decreased FS was considered a reduction in ADL of at least one category. Disorder of conscious (DOC) was defined as a Glasgow Coma Scale [10] score below 15, and for dementia patients, DOC was considered only if their consciousness was worse than their normal status. The key person (representing the main individual supporting the patient during and after admission) was classified as a child, spouse, or others. Rehabilitation included any type and intensity of physical rehabilitation program administered by physicians, physical therapists, and occupational therapists. The need for rehabilitation was determined during admission based on the risk of disuse syndrome or aspiration pneumonia. For survival patients, sites of acquisition were classified as home discharge (without nursing), home nursing, facility and transfer to another hospital.

\section{Patients}

Elderly hospitalized CAP patients were divided into two groups: maintained group, without deterioration of FS; and decreased group, with decreased FS. All enrolled cases had been diagnosed with CAP according to the definitions of the American Thoracic Society/Infectious Diseases Society of America guideline [11]. Patients who fulfilled all of the following inclusion criteria were enrolled in the study: 1 ) age $>64$ years; 2) symptoms compatible with pneumonia (e.g., fever, cough, sputum, pleuritic chest pain, or dyspnea); and 3) appearance of new pulmonary infiltrates consistent with pneumonia on chest X-ray or computed tomography. To ensure that all eligible cases were enrolled, the study investigators screened the hospital database for International Classification of Diseases, 10th revision (ICD-10) codes (J13-18, J69) and reviewed hospital medical records. Repeated episodes of pneumonia in the same patient within a 2-week period were regarded as a single episode.

\section{Exclusion criteria}

Cases of healthcare-associated pneumonia (HCAP) and hospital-acquired pneumonia (HAP) were excluded [12]. Cases with complications that occurred during admission (myocardial infarction, femoral fracture, cerebral infarction, etc.) that would have affected FS were also excluded.

\section{Outcomes}


The primary outcome was the effect of rehabilitation in preventing decreased FS. Demographic information, vital signs, including DOC and body mass index (BMI), laboratory values, and comorbidities were collected on admission. Comorbidities were identified according to the Charlson Comorbidity Index (CCI) [13]. The Pneumonia Severity Index (PSI) [14] score was calculated based on data obtained at the time of admission. Information regarding the key person was confirmed soon after admission. Information about acquisitions for survivors was also collected, and all patients who died were considered in-hospital deaths. Information of medical costs were collected at discharge.

\section{Statistical analyses}

The results are presented as numbers and percentages or medians and interquartile ranges unless otherwise indicated. Groups were compared using Wilcoxon rank-sum tests. In order to evaluate the effect of rehabilitation on FS, risk factors for decreased FS were determined using stepwise regression analysis. Confounding variables of decreased FS, age, sex, BMI, aspiration, dementia, DOC, undergoing rehabilitation, pre-admission $A D L, P S I, C C I$, and LOS were chosen as candidates with $p$ values below 0.2 on univariable analysis. Using the model of the minimum corrected Akaike's information criterion (AICC) in the backward direction, the final variables were determined. The effect of rehabilitation was evaluated by propensity score analysis by adjustment with variables determined on multivariable analysis. McNemar's test was performed to evaluate the effect of rehabilitation on preventing decreased FS in matched pairs. In all instances, two-tailed values of $p<0.05$ were considered significant. Data analysis was performed using JMP software (version 15.0; SAS Institute, Cary, NC).

\section{Results}

A total of 1854 patients diagnosed with pneumonia were identified. Of these, the following were excluded: 278 due to age $<65$ years; 612 due to outpatient treatment; 113 due to HCAP or HAP; and 215 due to incomplete data such as PSI, BI, etc. Of the 636 elderly patients with CAP, treatment was prolonged in 98 patients due to complications, even if pneumonia had resolved. The remaining 538 cases were included in the study, including 400 patients in the maintained group and 138 patients in the decreased group (Figure 1).

The participants were 370 men (68.8\%) and 168 women (31.2\%), with a median age of 79 years $(73,84$ years; first and third quartile, respectively). The background characteristics of these patients are summarized in Table 1. Sex, bedsores, and CCI were not significantly different between the groups. Patients in the decreased group were older, with higher rates of DOC and aspiration, and higher PSI categories. Patients in the decreased group had longer LOS (13 vs 27 days, respectively; $p<0.001$ ). Accordingly, a higher hospitalization cost was observed in the decreased group ( $\$ 4740$ vs $\$ 8667$, respectively; $p<001)$. The decreased group had a higher frequency of rehabilitation during hospitalization than the maintained group (189 (47.3\%) vs 104 (75.4\%), respectively; $p<0.001)$. The decreased group had higher frequencies of transfer to a nursing home or another facility or hospital $(p<0.001$, overall), and higher in-hospital mortality (8 (2.0\%) vs. $37(36.8 \%)$, respectively; $p<0.001)$. 
Multivariable analyses of factors contributing to decreased FS are shown in Table 2. Compared with the maintained group, the odds ratios for LOS, aspiration, age, and PSI of category V (refer IV+III+II) were 1.05 (95\% confidence interval (Cl), 1.04-1.07), 2.66 (95\% Cl, 1.58-4.49), 1.05 (95\% Cl, 1.02-1.09), and 1.92 $(95 \% \mathrm{Cl}, 1.29-3.44)$, respectively. $\mathrm{DOC}, \mathrm{BMI}$, and undergoing rehabilitation were not significantly different.

In order to check the effect of rehabilitation on preventing decreased FS, 166 cases were matched after propensity score analysis using variables identified on multivariate analysis (Table 3). Age, BMI, aspiration, DOC, LOS, and PSI category $\vee$ showed no significant differences. For the matched cases, McNemar's test was performed and showed no significant differences in preventing decreased FS between the two groups ( $p=0.327$; Table 4$)$.

\section{Discussion}

In this retrospective cohort study, prolonged LOS was observed in the decreased FS group. After multivariable regression analysis, LOS, aspiration pneumonia, age, and category V PSI were identified as independent factors contributing to decreased FS. There were 138 (25.7\%) elderly CAP patients who showed decreased FS in this study, which was higher than in previous studies [5, 6]. On propensity score analysis, after adjusting for age, BMI, aspiration pneumonia, DOC, LOS, and PSI, rehabilitation showed a limited effect in preventing decreased FS in elderly CAP patients.

The effects of rehabilitation have been evaluated from various aspects, but there was no definite conclusion. Some studies showed that early rehabilitation reduced LOS $[15,16]$ in pneumonia, but another study showed that it would prolong LOS [7]. The effects of rehabilitation on mortality and readmission rates were also unclear $[17,18]$. The present study showed that rehabilitation had a limited effect in preventing decreased FS in elderly CAP patients. This does not mean that rehabilitation is useless in CAP. Further research is warranted to find a more cost-effective approach to rehabilitation with adjustment for patient background and hospital characteristics.

There were other factors affecting decreased FS. Age-associated alterations not only decrease innate and adaptive immune responses, but they also involve structural and functional deteriorations of most physiological systems, which may negatively impact the ability of the individual to carry out ADL [19]. Aging is a major risk factor for the development of virtually every lung disease, with increased morbidity and mortality, whereas morbidities and mortalities from other prevalent diseases have decreased or remained stable [20].

In the process of aging, aspiration pneumonia, a subclass of CAP, is an increasing significant problem in elderly persons, and it is expected to contribute increasingly to mortality and morbidity in the elderly population over the coming decades [21]. Diagnosing aspiration pneumonia has been notoriously problematic because there have not been any established criteria for its diagnosis. Aspiration pneumonia is often diagnosed clinically, relying on the history and physical examination. Aspiration pneumonia accounts for $7-24 \%$ of CAP cases [22]. The rate of aspiration in the patients was $22.5 \%$ (overall), and up 
to $44.9 \%$ in the decreased group. Aspiration independently increased the risk of in-hospital mortality [23], and was also an independent factor related to decreased FS.

The PSI is considered the best predictor of mortality of CAP [14, 24]. Most patients who die from pneumonia are elderly, with multiple comorbidities and significant limitations in care put in place at or during admission. Surviving patients face the additional problem of decreased FS. According to the present study, FS tended to easily decrease in severe pneumonia. Decreased FS and LOS are important risk factors for unplanned re-hospitalization [25]. A prolonged LOS would result in a higher hospitalization cost. The average medical cost for the decreased group was almost double that of the maintained group. In addition to finding an effective method of rehabilitation, discharge planning might be necessary to decrease hospitalization costs.

\section{Limitations}

Some limitations to this study need to be considered when interpreting the present results. First, this study was limited to two medical facilities. Second, only CAP patients were included, and FS in HCAP or HAP is also important for elderly patients, but it remained unclear. Third, due to lack of information about cognitive function, a tool such as the Functional Independence Measure (FIM) [26] was not applicable. Fourth, FS was divided into three categories, whereas continuous variables might be more informative. Fifth, there were other factors, such as exercise, social issues, and economic situation, that could affect FS other than rehabilitation, but they were not included in the present study due to lack of information about them in the medical record.

\section{Conclusions}

The effect of rehabilitation is still unclear in CAP, and further research is warranted to analyze the costeffectiveness of rehabilitation.

\section{Abbreviations}

CAP: community-acquired pneumonia; FS: Functional status; ADL: activities of daily living; LOS: length of stay; BI: Barthel Index; DOC: disorder of conscious; ICD-10: International Classification of Diseases, 10th revision; AICc: corrected Akaike's information criterion; HCAP: healthcare-associated pneumonia; HAP: hospital-acquired pneumonia; BMI: body mass index; CCI: Charlson Comorbidity Index; PSI: Pneumonia Severity index; Cl: confidence interval; FIM: Functional Independence Measure.

\section{Declarations}

\section{Ethics approval and consent to participate}

Ethical approval for the study was obtained from the institutional review boards of Yokohama City University (B190600008) and Kanto Rosai Hospital (KR2018-29). 
Consent for publication

Not applicable.

\section{Availability of data and material}

The raw data are available by email on reasonable request to the corresponding author. E-mail: chinksmd@yahoo.co.jp

\section{Competing interests}

The authors declare that they have no competing interests.

\section{Funding}

Not applicable

\section{Authors' contributions}

$\mathrm{HC}, \mathrm{YH}$, and $\mathrm{NH}$ conceived of the study and participated in its design. YS did the main statistical analysis. $\mathrm{HC}, \mathrm{YH}, \mathrm{NH}, \mathrm{YS}$, and TK did critical reviews of the whole manuscript. $\mathrm{HC}$ collected and interpreted the data and was a major contributor to writing the manuscript. All authors read and approved the final manuscript.

\section{Acknowledgements}

The authors would like to thank and acknowledge the cooperation of all the participants in the study who volunteered their time and gave accounts of experiences without which none of the work would have been possible.

\section{References}

1. Organization WH: The top 10 causes of death. 2018, https://www.who.int/en/news-room/factsheets/detail/the-top-10-causes-of-death.

2. Wunderink RG, Waterer G: Advances in the causes and management of community acquired pneumonia in adults. Bmj 2017, 358:j2471.

3. Ishiguro T, Kagiyama N, Uozumi R, Odashima K, Kurashima K, Morita S, Takayanagi N: Risk factors for the severity and mortality of pneumococcal pneumonia: Importance of premorbid patients' performance status. $J$ Infect Chemother 2016, 22(10):685-691.

4. Haas A, Simone P: Frailty, leisure activity and functional status in older adults: relationship with subjective well being. Clin Gerontol 2013, 36:275-293.

5. Chen H, Hara Y, Horita N, Saigusa Y, Hirai Y, Kaneko T: Declined functional status prolonged hospital stay for community-acquired pneumonia in seniors. Clin Interv Aging 2020, Volume 15:1513-1519. 
6. Kosai K, Izumikawa K, Imamura Y, Tanaka H, Tsukamoto M, Kurihara S, Takazono T, Morinaga Y, Nakamura S, Miyazaki T et al: Importance of functional assessment in the management of community-acquired and healthcare-associated pneumonia. Intern Med 2014, 53(15):1613-1620.

7. Yagi M, Yasunaga H, Matsui H, Fushimi K, Fujimoto M, Koyama T, Fujitani J: Effect of early rehabilitation on activities of daily living in patients with aspiration pneumonia. Geriatr Gerontol Int 2016, 16(11):1181-1187.

8. Mahoney Fl, Barthel DW: Functional evaluation: The Barthel Index. Md State Med J 1965, 14:61-65.

9. Horita N, Miyazawa N, Yoshiyama T, Tsukahara T, Takahashi R, Tsukiji J, Kato H, Kaneko T, Ishigatsubo $\mathrm{Y}$ : Decreased activities of daily living is a strong risk factor for liver injury by antituberculosis drugs. Respirology 2013, 18(3):474-479.

10. Teasdale G, Jennett B: Assessment of coma and impaired consciousness. A practical scale. Lancet 1974, 2(7872):81-84.

11. Mandell LA, Wunderink RG, Anzueto A, Bartlett JG, Campbell GD, Dean NC, Dowell SF, File TM, Jr., Musher DM, Niederman MS et al: Infectious Diseases Society of America/American Thoracic Society consensus guidelines on the management of community-acquired pneumonia in adults. Clin Infect Dis 2007, 44 Suppl 2(Suppl 2):S27-72.

12. Kalil AC, Metersky ML, Klompas M, Muscedere J, Sweeney DA, Palmer LB, Napolitano LM, O'Grady NP, Bartlett JG, Carratala J et al: Management of adults with hospital-acquired and ventilatorassociated pneumonia: 2016 clinical practice guidelines by the Infectious Diseases Society of America and the American Thoracic Society. Clin Infect Dis 2016, 63(5):e61-e111.

13. Charlson ME, Pompei P, Ales KL, MacKenzie CR: A new method of classifying prognostic comorbidity in longitudinal studies: development and validation. J Chronic Dis 1987, 40(5):373-383.

14. Fine MJ, Auble TE, Yealy DM, Hanusa BH, Weissfeld LA, Singer DE, Coley CM, Marrie TJ, Kapoor WN: A prediction rule to identify low-risk patients with community-acquired pneumonia. $N$ Engl J Med 1997, 336(4):243-250.

15. Carratalà J, Garcia-Vidal C, Ortega L, Fernández-Sabé N, Clemente M, Albero G, López M, Castellsagué X, Dorca J, Verdaguer $\mathrm{R}$ et al: Effect of a 3-step critical pathway to reduce duration of intravenous antibiotic therapy and length of stay in community-acquired pneumonia: a randomized controlled trial. Arch Intern Med 2012, 172(12):922-928.

16. José A, Dal Corso S: Inpatient rehabilitation improves functional capacity, peripheral muscle strength and quality of life in patients with community-acquired pneumonia: a randomised trial. $J$ Physiother 2016, 62(2):96-102.

17. Larsen T, Lee A, Brooks D, Michieli S, Robson M, Veens J, Vokes O, Lucy SD: Effect of Early Mobility as a Physiotherapy Treatment for Pneumonia: A Systematic Review and Meta-Analysis. Physiother Can 2019, 71(1):82-89.

18. Momosaki R, Yasunaga $\mathrm{H}$, Matsui $\mathrm{H}$, Horiguchi H, Fushimi K, Abo M: Effect of early rehabilitation by physical therapists on in-hospital mortality after aspiration pneumonia in the elderly. Arch Phys Med Rehabil 2015, 96(2):205-209. 
19. Roberts CE, Phillips LH, Cooper CL, Gray S, Allan JL: Effect of different types of physical activity on activities of daily living in older adults: systematic review and meta-analysis. J Aging Phys Act 2017, 25(4):653-670.

20. Thannickal VJ, Murthy M, Balch WE, Chandel NS, Meiners S, Eickelberg O, Selman M, Pardo A, White ES, Levy BD et al: Blue journal conference. Aging and susceptibility to lung disease. Am J Respir Crit Care Med 2015, 191(3):261-269.

21. Rodriguez $A E$, Restrepo MI: New perspectives in aspiration community acquired Pneumonia. Expert Rev Clin Pharmacol 2019, 12(10):991-1002.

22. Reza Shariatzadeh M, Huang JQ, Marrie TJ: Differences in the features of aspiration pneumonia according to site of acquisition: community or continuing care facility. J Am Geriatr Soc 2006, 54(2):296-302.

23. Komiya K, Rubin BK, Kadota JI, Mukae H, Akaba T, Moro H, Aoki N, Tsukada H, Noguchi S, Shime N et al: Prognostic implications of aspiration pneumonia in patients with community acquired pneumonia: A systematic review with meta-analysis. Sci Rep 2016, 6:38097.

24. Murcia J, Llorens P, Sánchez-Payá J, Reus S, Boix V, Merino E, Laghzaoui F, Portilla J: Functional status determined by Barthel Index predicts community acquired pneumonia mortality in general population. $J$ Infect 2010, 61(6):458-464.

25. Morandi A, Bellelli G, Vasilevskis EE, Turco R, Guerini F, Torpilliesi T, Speciale S, Emiliani V, Gentile S, Schnelle $\mathrm{J}$ et al: Predictors of rehospitalization among elderly patients admitted to a rehabilitation hospital: the role of polypharmacy, functional status, and length of stay. J Am Med Dir Assoc 2013, 14(10):761-767.

26. Keith RA, Granger CV, Hamilton BB, Sherwin FS: The functional independence measure: a new tool for rehabilitation. Adv Clin Rehabil 1987, 1:6-18.

\section{Tables}

Table 1. Demographic characteristics and outcomes of the maintained and decreased functional status groups 


\begin{tabular}{|c|c|c|c|c|}
\hline & $\begin{array}{l}\text { Total } \\
\mathrm{n}=538\end{array}$ & $\begin{array}{l}\text { Maintained group } \\
\mathrm{n}=400\end{array}$ & $\begin{array}{l}\text { Decreased group } \\
\mathrm{n}=138\end{array}$ & $\mathrm{p}$-value \\
\hline Age (years) & $79(73-84)$ & $77(71.3-83)$ & $82(76-86.3)$ & $<0.001$ \\
\hline Sex (male/female) & $168 / 370$ & $131 / 269$ & $37 / 101$ & 0.194 \\
\hline $\operatorname{BMI}\left(\mathrm{kg} / \mathrm{m}^{2}\right)$ & $19.3(16.6-22.3)$ & $19.7(16.7-22.6)$ & $18.6(16.4-20.9)$ & 0.002 \\
\hline Dementia & $66(12.3 \%)$ & $41(10.3 \%)$ & $25(18.1 \%)$ & $<0.001$ \\
\hline DOC & $158(29.4 \%)$ & $91(22.8 \%)$ & $67(48.6 \%)$ & $<0.001$ \\
\hline Bedsore & $15(2.8 \%)$ & $11(2.8 \%)$ & $4(2.9 \%)$ & 0.927 \\
\hline Aspiration pneumonia & $121(22.5 \%)$ & $59(14.8 \%)$ & $62(44.9 \%)$ & $<0.001$ \\
\hline In rehabilitation & $293(54.5 \%)$ & $189(47.3 \%)$ & $104(75.4 \%)$ & $<0.001$ \\
\hline CCI & & & & 0.445 \\
\hline $\mathrm{CCI} \leq 1$ & $167(31.0 \%)$ & 127 (31.8\%) & $40(29.0 \%)$ & \\
\hline $\mathrm{CCI}=2$ & $150(27.9 \%)$ & $115(28.8 \%)$ & $35(25.4 \%)$ & \\
\hline $\mathrm{CCI} \geq 3$ & $221(41.1 \%)$ & $158(39.5 \%)$ & $63(45.7 \%)$ & \\
\hline PSI category & & & & $<0.001$ \\
\hline II & $22(4.1 \%)$ & $21(5.25 \%)$ & $1(0.7 \%)$ & \\
\hline III & 107 (19.9\%) & $90(22.5 \%)$ & 17 (12.3\%) & \\
\hline IV & 225 (41.8\%) & $173(43.3 \%)$ & $52(37.7 \%)$ & \\
\hline $\mathrm{V}$ & $184(34.2 \%)$ & $116(29.0 \%)$ & $68(49.3 \%)$ & \\
\hline ADL before admission & & & & $<0.001$ \\
\hline Independent & 367 (68.2\%) & $280(70.0 \%)$ & $87(63.0 \%)$ & \\
\hline Semi-dependent & $127(23.6 \%)$ & $76(19.0 \%)$ & $51(37.0 \%)$ & \\
\hline Dependent & $44(8.2 \%)$ & $44(11.0 \%)$ & $0(0.0 \%)$ & \\
\hline ADL after admission & & & & $<0.001$ \\
\hline Independent & $291(54.1 \%)$ & $291(72.8 \%)$ & $0(0.0 \%)$ & \\
\hline Semi-dependent & $121(22.5 \%)$ & 65 (16.3\%) & $56(40.6 \%)$ & \\
\hline Dependent & $126(23.4 \%)$ & $44(11.0 \%)$ & $82(59.4 \%)$ & \\
\hline LOS (days) & $15(9-26)$ & $13(9-19.8)$ & $27(14-46.3)$ & $<0.001$ \\
\hline Survival outcome & & & & $<0.001$ \\
\hline Home & $275(51.1 \%)$ & $271(67.8 \%)$ & $4(2.9 \%)$ & \\
\hline Home nursing & $135(25.1 \%)$ & $85(21.3 \%)$ & $50(36.2 \%)$ & \\
\hline Facility & $42(7.8 \%)$ & $20(5.0 \%)$ & $22(15.9 \%)$ & \\
\hline Hospital & $41(7.6 \%)$ & $16(4.0 \%)$ & $25(18.1 \%)$ & \\
\hline In-hospital mortality & $51(9.2 \%)$ & $8(2.0 \%)$ & $37(26.8 \%)$ & $<0.001$ \\
\hline Key person & & & & 0.013 \\
\hline Children & $239(44.5 \%)$ & $163(40.9 \%)$ & $76(50.1 \%)$ & \\
\hline Spouse & $256(47.7 \%)$ & $204(51.1 \%)$ & $52(37.7 \%)$ & \\
\hline Others & $42(7.8 \%)$ & $32(8.0 \%)$ & $10(7.3 \%)$ & \\
\hline Cost (\$) & 5231 (3822-7989) & 4740 (3542-6488) & 8667 (4985-12901) & $<0.001$ \\
\hline
\end{tabular}


BMI, body mass index; DOC, disorder of consciousness; CCI, Charlson Comorbidity Index; PSI, Pneumonia Severity Index; ADL, activities of daily living; LOS, length of stay.

Table 2. Multivariable analyses of factors affecting decreased functional status

\begin{tabular}{|c|c|c|c|c|}
\hline & \multirow[b]{2}{*}{$\mathrm{OR}$} & \multicolumn{2}{|c|}{$95 \%$ CI } & \multirow[b]{2}{*}{$\mathrm{p}$ value } \\
\hline & & Lower limit & Upper limit & \\
\hline LOS & 1.05 & 1.04 & 1.07 & $<0.001$ \\
\hline Aspiration pneumonia & 2.66 & 1.58 & 4.49 & $<0.001$ \\
\hline Age & 1.05 & 1.02 & 1.09 & 0.001 \\
\hline PSI of category V & 1.92 & 1.29 & 3.44 & 0.010 \\
\hline DOC & 1.59 & 0.95 & 2.64 & 0.078 \\
\hline BMI & 0.95 & 0.90 & 1.02 & 0.165 \\
\hline Rehabilitation & 1.52 & 0.90 & 2.56 & 0.114 \\
\hline
\end{tabular}

OR, odds ratio; CI, confidence interval; LOS, length of stay; PSI, Pneumonia Severity Index; DOC, disorder of consciousness; BMI, body mass index.

Table 3. Detailed information of cases matched by propensity score

\begin{tabular}{lcccccc}
\hline & \multicolumn{3}{c}{ Before matching } & \multicolumn{3}{c}{ After matching } \\
\hline & \multicolumn{2}{c}{ In rehabilitation } & p-value & In rehabilitation & p-value \\
\cline { 3 - 6 } & Yes & No & & Yes & No & \\
& $\mathrm{n}=245$ & $\mathrm{n}=292$ & & $\mathrm{n}=166$ & $\mathrm{n}=166$ & \\
\hline Age (y) & 80 & 78 & $<0.001$ & 78 & 79 & 0.767 \\
BMI (kg/m $\left.{ }^{2}\right)$ & 18.8 & 19.7 & $<0.001$ & 19.9 & 18.6 & 0.934 \\
\hline Aspiration & $97(33.1 \%)$ & $24(9.8 \%)$ & $<0.001$ & $27(16.3 \%)$ & $23(13.9 \%)$ & 0.539 \\
\hline DOC & $100(34.1 \%)$ & $58(23.7 \%)$ & 0.008 & $46(27.1 \%)$ & $45(27.7 \%)$ & 0.727 \\
\hline LOS (days) & 19 & 11 & $<0.001$ & 14 & 14 & 0.835 \\
\hline PSI V & $100(34.1 \%)$ & $84(34.3 \%)$ & 0.98 & $55(33.1 \%)$ & $56(33.7 \%)$ & 0.907 \\
\hline
\end{tabular}

CAP: community-acquired pneumonia; DOC, disorder of consciousness; LOS: length of stay; PSI, pneumonia severity index.

Table 4. The effect of rehabilitation in elderly CAP patients 


\begin{tabular}{lllll}
\hline & & \multicolumn{3}{c}{ With rehabilitation } \\
& & Decreased & Maintained & Total \\
\hline Without rehabilitation & Decreased & 7 & 19 & 26 \\
& Maintained & 26 & 114 & 140 \\
\cline { 2 - 5 } Total & & 33 & 133 & 166 \\
\hline p-value & & \multicolumn{3}{c}{$\mathrm{p}=0.327$} \\
\hline
\end{tabular}

CAP: community-acquired pneumonia

Figures

\section{Pneumonia patients $(n=1854)$}

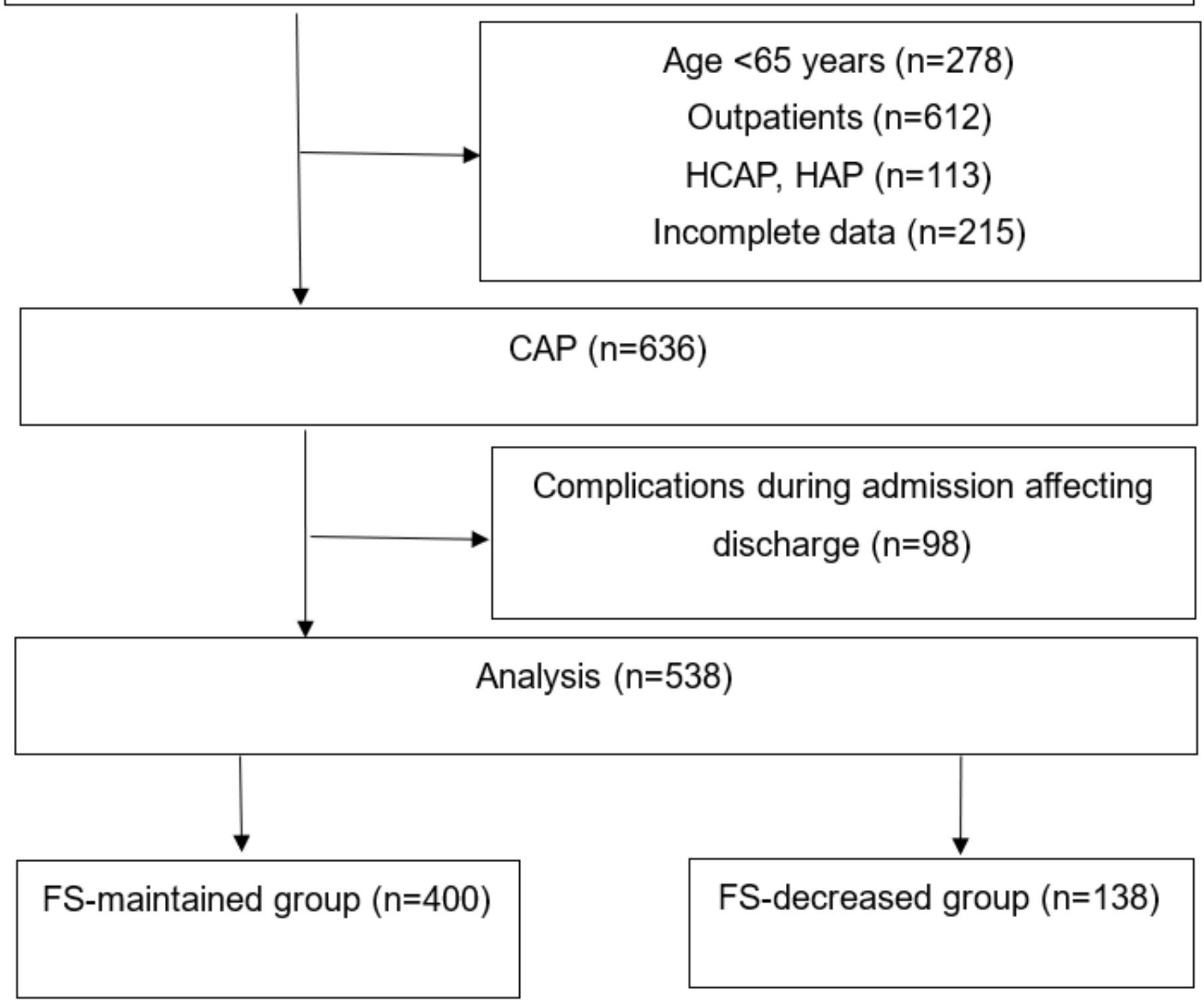




\section{Figure 1}

Flowchart of the study HCAP, healthcare-associated pneumonia; HAP, hospital-acquired pneumonia; CAP, community-acquired pneumonia. 